\title{
A política Cultural da Capoeira Contemporânea: uma Etnografia Sobre os Casos Brasileiro e Português
}

\author{
Celso de Brito ${ }^{1}$
}

\begin{abstract}
Resumo
Uma etnografia sobre a transnacionalização do Grupo de Capoeira Angola Irmãos Guerreiros (GCAIG) nos conduziu a duas categorias que qualificam diferentes formas de Capoeira: "esporte" e "cultura". O uso nativo de tais noções remete à existência de disputas no campo da Capoeira que associam "cultura" com um saber "tradicional" e "esporte" com um saber "erudito". Visamos aqui descrever algumas implicações políticas desses usos em dois contextos contemporâneos: Brasil e Portugal. Concluímos que a perspectiva "cultural" ganha força no Brasil gerando espaço para a multiplicidade de saberes nativos, enquanto que em Portugal a perspectiva "esportiva" prevalece submetendo grupos de diferentes vertentes a uma única forma de organização.
\end{abstract}

Palavras-chave: Capoeira. Política cultural. Brasil. Portugal.

\section{The Cultural Politics of Contemporary Capoeira: an Ethnography of Brazilian and Portuguese Cases}

\begin{abstract}
An ethnography of the transnationalization of the Irmãos Guerreiros Capoeira Angola Group (GCAIG) led us to two categories that qualify distinct Capoeira conceptions: "sport" and "culture". The native use of such notions refers to the existence of disputes within Capoeira which associate "culture" with an appreciation of traditional knowledge and "sport" with an appreciation of a scholarly knowledge. Our purpose in this article is to describe some political implications of these uses in two contemporary contexts: Brazil and Portugal. We conclude that the "cultural"

1 Doutor em Antropologia pela UFRGS/RS e professor da Universidade Federal do Piauí (UFPI), Brasil. celsodebrito@yahoo.com.br
\end{abstract}


perspective gained strength in Brazil, generating space for the multitude of traditional knowledge, while in Portugal the "sport" perspective prevails submitting groups of different traditions to a single form of organization.

Keywords: Capoeira. Cultural politics. Brazil. Portugal.

\section{INTRODUÇão}

Os escritos sobre a Capoeira surgem no final do século XIX e início do século XX. Nas primeiras décadas do século XX, já havia uma divisão entre duas distintas abordagens: uma atribuindo ênfase a criação e sistematização de uma linguagem "esportiva" mais palatável à elite brasileira afeita ao positivismo e ao higienismo (BURLAMAQUI, 1928; MARINHO, 1982) e outra enfatizando a importância da herança africana para a "cultura" brasileira (CARNEIRO, 1981; QUERINO, 1938). Já poderíamos antever uma distinção e oposição no interior da própria "Capoeira moderna" (ASSUNÇÃO, 2014) que surgiria na década de 1940. A expressão "Capoeira moderna" refere-se ao fato de que ambas as modalidades sofreram influência do contexto brasileiro, no qual foi forjada sua identidade nacional sob a égide do "progresso": se a Capoeira Regional nascia "moderna", a Capoeira Angola, já praticada anteriormente, passava por algumas ressignificações modernizantes mediante, contudo, a auto atribuição de "tradicional".

No campo empírico, a Capoeira Angola manteve-se como a Capoeira "tradicional" pela via da reivindicação à herança cultural africana, enquanto que a Capoeira Regional se vinculou à noção de «modernidade», conformando-se aos valores da recém instaurada identidade mestiça brasileira e associando-a à ideia de "esporte nacional". Desse modo, para muitos sentidos, a noção de "esporte" se conecta à noção de «modernidade», da mesma forma que a noção de "cultura" se associa à noção de "tradição", como veremos no decorrer do artigo. 
Depois da primeira metade do século $X X$, as reflexões acadêmicas sobre Capoeira escassearam até que, no final da década de 1980, surge um artigo importante em uma abordagem antropológica publicado na Revista Brasileira de Ciências Sociais demonstrando as transformações pelas quais a Capoeira passou durante sua difusão do nordeste ao sudeste brasileiro: "Capoeira, de arte negra a esporte branco", de Alejandro Frigerio (1989).

Esse artigo reanimou os estudos sobre Capoeira enfatizando as alterações dos rituais e das representações dos capoeiristas relacionadas à interdependência de dois movimentos: 1) movimento geográfico, sobre a imigração de mestres baianos ao sul/sudeste do Brasil e 2) movimento social, sobre a inserção da prática da Capoeira nas camadas mais abastadas da sociedade brasileira. Frigerio (1989) analisou essas alterações e ressaltou uma distinção conceitual que surgia entre os capoeiristas daquele período - talvez em função de uma reflexividade em relação aos trabalhos acadêmicos: "arte negra tradicional" (Capoeira Angola) a "esporte branco" (Capoeira Regional).

Notemos que nos escritos de Frigerio (1989) a concepção "esportizada" da Capoeira está associada a um processo de "branqueamento" contra o qual grupos de Capoeira Angola se organizaram nas décadas de 1980-1990 através da mobilização política dos conceitos de "cultura" e de "tradição" num processo denominado de "etnopolítica" (AGIER, 1992). Naquele período, a Capoeira Angola ou "arte negra tradicional" passou por um processo de revitalização que conduziu muitos dos capoeiristas por um novo contra fluxo das conversões que ocorriam até a década de 1980, cujo sentido passou a ser do "esporte branco" (Capoeira Regional) à "arte negra tradicional" (Capoeira Angola revitalizada).

Na primeira década do século XXI o embate entre Capoeira "esporte" e Capoeira "cultura" adentra no cenário político nacional 
em torno das leis de profissionalização do capoeirista, opondo, de um lado, aqueles que defendem que a Capoeira seja um saber "cultural" (e, assim sendo, reivindicam o direito dos mestres de ensiná-la segundo seus próprios princípios) e, de outro lado, aqueles que defendem que a Capoeira seja um "esporte" (e portanto reivindicam que seu ensino deve se restringir aos professores com formação em Educação Física, segundo o saber universitário e subordinado aos critérios do CONFEF - Conselho Federal de Educação Física - e/ou das Federações Esportivas).

No Brasil, a perspectiva "cultural" da Capoeira tem resistido às constantes tentativas de regulação da profissão do capoeirista por parte do CONFEF, sobretudo devido ao Registro da Capoeira como "Patrimônio da Cultura Imaterial Nacional", em 2007. Em Portugal, a mesma questão foi posta em 2014 e a concepção de Capoeira "esporte" venceu a querela. A partir daquele momento, o ensino da Capoeira passou a ser regido pelos critérios dispostos na lei 5/2007 de Bases da Atividade Física e do Desporto. Tal categorização ocorreu à revelia da opinião de muitos mestres e professores de Capoeira residentes em Portugal (que por sua vez, não se mobilizaram politicamente a tempo) e das definições que constam no Registro da Capoeira como Patrimônio da Cultura Imaterial da Humanidade, realizado no mesmo ano em Paris.

Com isso, a lei portuguesa resguarda assim o direito de ensinar Capoeira em território nacional apenas àqueles que se enquadrarem nos critérios "esportivos" definidos pela Secretaria do Desporto e pela Federação Portuguesa de Capoeira.

Vemos que o processo de transnacionalização da Capoeira contemporânea nos permite concluir que - mesmo tendo havido uma considerável revitalização da Capoeira em termos de valorização da cultura afro-brasileira e de seus conhecedores, assim como um reconhecimento mundial de seu caráter cultural - o governo de 
Portugal posiciona-se em direção oposta às políticas de valorização do saber definido como "tradicional" por esse segmento.

Antes de prosseguirmos há, contudo, a necessidade de explicitarmos o que entendemos por "tradição" da Capoeira.

A ideia de "tradição" é aqui compreendida como um conceito construído e validado a partir de disputas simbólicas entre vários agentes, incluindo o Estado brasileiro, capoeiristas e intelectuais em dois contextos históricos e sociais específicos: o primeiro, relativo aos anos 1930-1940 nos quais houve a modernização da Capoeira e o segundo, concernente ao período 1970-1980, quando a Capoeira Angola passou pelo processo de revitalização e foram criadas as Federações. Em ambos os momentos, deu-se um processo de construção identitária que chamamos, em outro texto, de "identidades contrastivas da Capoeira" (BRITO, 2010). Aqui apresentaremos um desdobramento da "tradição", construída nos momentos anteriormente citados, considerando a ressignificação da "tradição" da Capoeira Angola na Europa do século XXI.

Em todos esses momentos, entendemos que a "tradição da Capoeira" compõe o polo relacionado à Capoeira Angola na oposição basilar presente na construção das identidades do universo da Capoeira, enquanto que a "modernidade" ocupa o polo oposto relacionado, por sua vez, à Capoeira Regional. Sem a intenção de nos alongarmos em demasia nessa discussão, entendemos a "tradição da Capoeira" como o substrato do que os capoeiristas vieram a denominar de Capoeira "cultura", enquanto que a "modernidade da Capoeira" seria o substrato da noção de Capoeira "esporte".

Cremos estar sendo mais fidedignos com a natureza de nosso trabalho atribuindo o protagonismo dessa análise às noções nativas de "cultura" e de "esporte" mais do que as noções de "tradição" e "modernidade", tendo em vista que parecem ser elas mesmas a chave de entendimento para o fenômeno que chamamos de "política 
cultural da Capoeira contemporânea" mantendo, por certo, a noção de "tradição" em nosso horizonte analítico.

Talvez possamos, no restante desse artigo, entender o caminho pelo qual acepções relacionadas à "tradição" alimentam as diferentes concepções de Capoeira "cultura" operacionalizadas no campo político pelos capoeiristas contemporâneos no Brasil e em Portugal.

\section{A Dinamicidade das Noções de “Cultura" e “Esporte" no}

\section{Grupo de Capoeira Angola Irmãos Guerreiros (GCAIG)}

Frigerio (1989) analisa as transformações da Capoeira no período entre 1930 e 1980, passando pela formação da Capoeira Regional Baiana até a formalização da Capoeira "esporte", em 1970, na cidade de São Paulo, tendo como base a discussão realizada por Ortiz (1978) que por sua vez pensava a Umbanda do Rio de Janeiro através de um contínuum entre duas referências: Candomblé baiano e o Kardecismo de origem europeia.

Sobre esse pano de fundo, Frigerio (1989) descreveu a transformação da "arte negra tradicional" em "esporte branco" com base na perda de oito elementos fundamentais da cultura afro-brasileira soteropolitana: 1) "Malícia"; 2) “Complementação"; 3) "Jogo baixo"; 4) "Ausência de violência"; 5) "Movimentos bonitos"; 6) "Música lenta"; 7) "Importância do ritual" e 8) "Teatralidade".

Sintetizando os argumentos do autor, a Capoeira teria se "embranquecido" na medida em que passava a enfatizar a violência através da incorporação de golpes de esportes de luta reconhecidos pela Educação Física, na mesma proporção em que perdia o rigor para com os procedimentos rituais ancorados, até então, na conexão entre a música lenta e jogos baixos e que foram substituídos por performances individualizadas, movimentos rápidos e saltos mortais da Ginástica Olímpica. 
Ainda na década de 1980, surge uma resposta a essas chamadas deturpações. O GCAP (Grupo de Capoeira Angola Pelourinho) associou-se ao Movimento Negro e revitalizou a Capoeira Angola segundo um resgate da tradição africana e crítica ao processo de colonização dos ocidentais no Brasil e na África, como afirmam muitos mestres desta linhagem desde aquele período até os dias atuais (BRITO, 2015).

A partir da década seguinte, a Capoeira Angola revitalizada em Salvador chega até o sudeste do Brasil. Em São Paulo, muitos dos membros de grupos de Capoeira "esportizada" convertem-se para a Capoeira Angola revitalizada, alterando sua concepção "esportiva" para outra considerada "cultural". Esse movimento acerca da Capoeira que praticavam fundamentou-se na responsabilidade de (re) africanizar a Capoeira através de símbolos do Candomblé e estabelecer críticas ao colonialismo europeu pela via da "etnopolítica" (AGIER, 1992) construída durante uma associação com o Movimento Negro.

\section{Do "esporte" À "CUltura": A CONSTRUÇÃo da tradição etnopolitizada do Grupo de Capoeira Angola Irmãos Guerreiros em São Paulo}

O responsável pela disseminação de núcleos do Grupo Irmãos Guerreiros na Europa (entre os quais está o português que será analisado a seguir) é Mestre Perna (Márcio Lourenço Araújo); natural de Taboão da Serra, São Paulo. Filho de imigrantes baianos, Mestre Perna começa a praticar Capoeira aos 10 anos de idade com Mestre Milton e Mestre Alcides. Na adolescência, conhece Mestre Marrom, que na ocasião era responsável pelo Grupo Falange de Capoeira Regional. Mestre Marrom, por sua vez, havia treinado com Mestre Boneco e com Mestre Meinha, alguns dos mestres baianos que levaram a Capoeira Regional para a capital paulista e que viveram os tempos de Federação e "esportização" da Capoeira naquela cidade. 
Na década de 1990, os mestres soteropolitanos de Capoeira Angola passaram a viajar para o sudeste disseminando a Capoeira Angola revitalizada - entenda-se (re)africanizada. Levados por esse novo movimento, Mestre Marrom e seus alunos mais velhos decidiram se dedicar apenas à essa forma de Capoeira e iniciaram uma conversão, acompanhando os treinamentos de Mestre Pé de Chumbo que, juntamente como Mestre Plínio, foi um dos primeiros mestres da Capoeira Regional de São Paulo a fazer tal conversão para a Capoeira Angola.

A Capoeira Angola soteropolitana assumia em São Paulo ares da "tradição afro-brasileira" em posição à "moderna" e "esportivizada" Capoeira Regional defendida pelas Federações paulistas.

Com os ensinamentos das aulas de Mestre Pé de Chumbo e das oficinas ministradas pelos mestres baianos, Mestre Marrom reproduzia a Capoeira Angola baiana para seus discípulos paulistas em sua academia no Taboão da Serra. Mas não se tratava apenas de aprender movimentos, tratava-se de embebedar-se da "tradição afro-baiana", pois como dizem os mestres de Capoeira Angola desta localidade ser angoleiro (praticante de Capoeira Angola) não é só jogar a perna para o ar. Essa expressão refere-se ao fato de que Capoeira Angola não é apenas uma prática corporal, mas algo também abstrato e relacionado ao campo dos valores morais. A "tradição da Capoeira afro-baiana" não se restringe a uma corporeidade específica, mas a um posicionamento etnopolítico, mais especificamente, a comprar os valores (re)africanistas oriundos do Movimento Negro da década de 1980.

Nessa nova fase, Mestre Marrom e seus irmãos (mestres Baixinho, Macete e Guerreiro) criaram o Grupo de Capoeira Angola Irmãos Guerreiros, cuja liderança foi delegada ao Mestre Marrom, razão pela qual as cores utilizadas pelo grupo são marrom e branca, como podemos ver a seguir: 


\section{Figura 1 - Símbolo do Grupo de Capoeira Angola Irmãos Guerreiros}

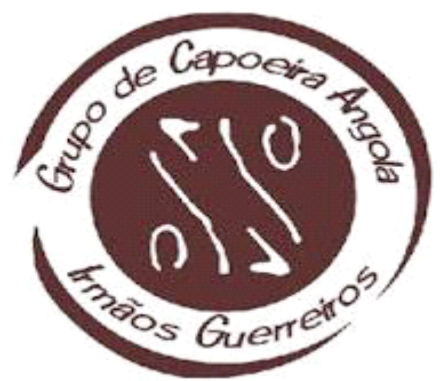

Fonte: Grupo de Capoeira Angola Irmãos Guerreiros (2016).

Logo, as estratégias levadas a cabo pelos mestres da Capoeira Angola de Salvador da década de 1980 passaram a ser contextualizadas em São Paulo como a Capoeira "tradicional".

A aproximação do Grupo às manifestações culturais afrobrasileiras como o Candomblé e o samba de roda se intensificam. O espaço de treino passa a ser chamado "Senzalinha" e campanhas para (re)africanização são realizadas como a que vemos nas imagens a seguir:

Figura 2 - Participação do Grupo de Capoeira Angola Irmãos Guerreiros (Mestre Marrom à esquerda e Mestre Perna à direita) na CAMPANHA "EU AFRICANIZO SP

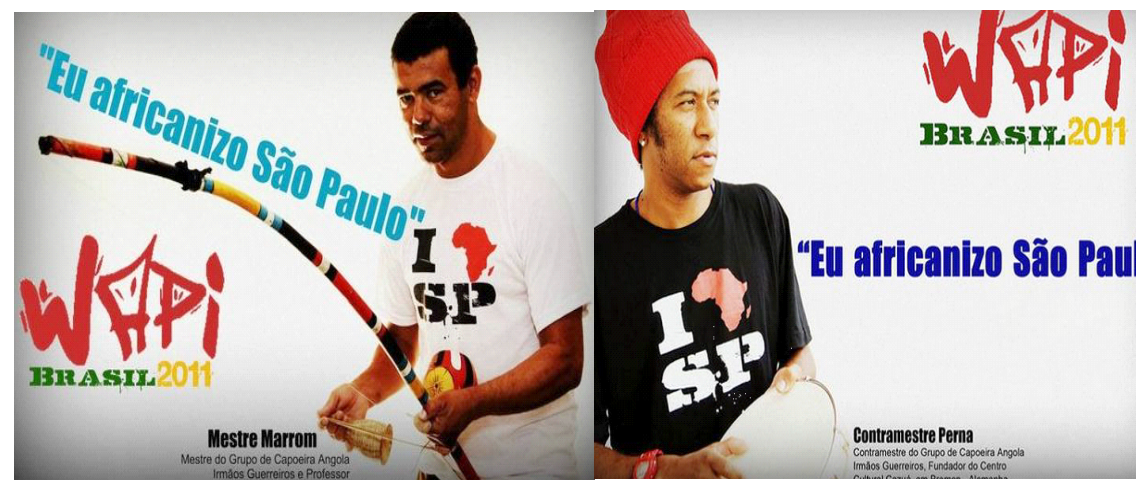

Foto: Léo Guma (2011). Fonte: Grupo de Capoeira Angola Irmãos Guerreiros (2016). 
Atualmente, o Grupo Irmãos Guerreiros é considerado um dos grupos "tradicionais" da Capoeira Angola paulista e um dos grupos de grande destaque na Europa.

\section{Do "esporte" à "CUltura": A tradição apolítica do Grupo IrMÃos GUERREIros NA EUROPA}

Em 2002, Mestre Perna ruma para Bremen-Alemanha, a convite de um grupo de capoeiristas alemães para permanecer por cerca de 2 anos ensinando Capoeira Angola. Após os dois anos decorridos, Mestre Perna decide fundar uma Associação Cultural e permanecer na Alemanha por prazo indefinido. Assim nasce o núcleo alemão do Grupo de Capoeira Angola Irmãos Guerreiros, em 2004.

Desde então, a Associação Cultural Cazuá reúne uma equipe de representantes da "cultura tradicional afro-brasileira": Babalorixá Muralemsibe, professor Kenneth, Professor Bom Baiano, Miguel Arruda e contramestre Forró (Joelson Menezes). Mestre Perna explica a formação de sua Associação Cultural Cazuá dizendo:

Os novos representantes, das novas gerações da cultura
afro-brasileira de São Paulo como eu não têm tanta
familiaridade com a cultura africana tradicional quanto
quem é de Salvador, que vive com isso desde criança.
Mas é por isso mesmo que essa nova galera se destaca,
entendeu? Porque a gente tem que pesquisar mesmo a
cultura, a gente reúne muito dessa cultura, tá entendendo?
Aí a gente traz também a cultura afro de outras regiões
do país, como o maracatu, tambor de crioula, o jongo, o
samba de coco, o Candomblé e fortalece mesmo o lado
cultural da tradição da Capoeira Angola

Miguel Arruda é um músico da cidade de Londrina, no Paraná. Atualmente reside em Porto-Portugal, onde trabalha com bandas de música popular brasileira realizando shows de "samba de

2 Fala de Mestre Perna, em entrevista concedida ao autor deste artigo, na cidade de Berlim, em 2013. 
roda" ou "samba coco" com Mestre Perna, durante as festas noturnas dos eventos de Capoeira. Contramestre Forró é discípulo de Mestre Marrom do Grupo de Capoeira Angola Mestre Marrom e Alunos (GCAMA). Além de capoeirista é candomblecista e grande conhecedor de manifestações culturais afro-brasileiras, como maracatu, jongo e tambor de crioula; ele reside e trabalha com cultura afro-brasileira em Hanôver, Alemanha. Babalorixá Muralemsibe, conhecido pelos membros do grupo como Mestre Murah, oferece aulas de dança afro e danças de orixás. Ao menos uma vez por ano, o grupo se reúne em Berlim durante a festa da iabá Iansã, o orixá de Babalorixá Muralemsibe, para a realização de uma roda de Capoeira Angola em pleno ritual religioso em seu Ilê Obá Silekê, em Berlim, Alemanha (BRITO, 2016).

Podemos cogitar a ideia de que na passagem do Brasil para a Europa, o que é entendido como "tradição" mantém uma aura abstrata, não se restringindo à prática corporal, ao jogar a perna para o ar, inserindo sua (re)africanização no campo da cultura e da religiosidade afro-brasileira (BRITO, 2016), mas há indícios que apontam para uma despolitização dessa "tradição" construída na Europa, sendo enfatizado seu caráter religioso e de entretenimento.

Essa afirmação é balizada em vários depoimentos e práticas da Capoeira no continente europeu. Um exemplo lapidar nos é oferecido pelo professor Kenneth, atualmente membro do Grupo Irmãos Guerreiros de Capoeira Angola e antigo membro do GCAP (Grupo responsável pela aliança com o Movimento Negro no Brasil na década de 1980), que assim disse: "eu vim de uma linhagem politizada da Capoeira, lá no GCAP, a gente fazia grupo de estudo e tudo, seminários com a galera do Movimento Negro, mas aqui eu não tenho isso, eu não faço política com a Capoeira, aqui na Europa isso não acontece".

Após alguns anos, o GCAIG se espalhou por outros países da Europa, sendo um deles Portugal. 


\section{O Grupo Irmãos Guerreiros lisboeta: percursos e}

REPRESENTAÇÕes dos CAPOEIRISTAS SOBRe "ESPORTE" E "CUltura"

Segundo um levantamento realizado nos anos de 2013-2014, há cerca de 50 grupos de Capoeira Regional em Portugal e apenas 2 grupos de Capoeira Angola, enquanto que em outros países europeus o número de grupos deste segundo segmento é muito maior.

Treinel Grego, como é conhecido Sifis Papageorgiou, é o fundador do núcleo lisboeta do GCAIG. Ele praticou Capoeira Regional com Mestre Paulinho em Atenas, Grécia, onde morava. Em 2008, terminou seus estudos em Engenharia Naval e mudou-se para Oslo, na Noruega. Em Oslo, começou a praticar Capoeira junto a um grupo de jovens que começava a se aproximar de Mestre Perna e da Capoeira Angola.

Treinel Grego diz ter conhecido a Capoeira Angola ainda em Atenas, quando Mestre Paulinho convidou Mestre Cobra Mansa para realizar uma oficina. Ele conta que na ocasião a Capoeira Angola não lhe agradou por que o que ele buscava era uma atividade física e esportiva, o que tornava a Capoeira Regional mais atraente. Nesse momento, para treinel Grego, a "tradição" não era uma de suas exigências.

No período em que morou em Oslo, treinel Grego não se adequou à cidade e decidiu mudar-se para Bremen, onde passou o ano de 2010 treinando com Mestre Perna. No entanto, ao final daquele ano, ele conseguiu um trabalho em Lisboa e mudou-se novamente. Lá chegando, procurou pela Capoeira Angola, mas foi em vão. Ao frequentar os grupos locais acabou por conhecer outros praticantes de Capoeira Angola que, assim como ele, acabavam de chegar na cidade e não se identificavam com os grupos lisboetas, justamente por eles reunirem as características elencadas por Frigerio (1989) quando esse descrevia o "esporte branco": violência exacerbada, jogo alto e rápido, ausência de ritual e musicalidade, além de performances individuais 
com saltos de Ginástica Olímpica. Esse foi o momento no qual treinel Grego percebeu ter absorvido as condições necessárias para reconhecer e valorizar o que ele entende hoje por "tradição" da Capoeira Angola.

Grego e seus novos companheiros, desprezando o que entendiam como prática esportiva da Capoeira decidiram, então, reunir-se semanalmente para praticarem a Capoeira Angola juntos. $\mathrm{Na}$ ocasião, ele namorava sua futura esposa, treinel Pintinha (Elisa Doolitle), que havia conhecido durante um dos eventos do núcleo austríaco do GCAIG. Ambos decidiram morar juntos em Lisboa e lá organizaram um núcleo do Grupo Irmãos Guerreiros.

Em 2014, o núcleo era formado por 16 capoeiristas de diversas nacionalidades, uma vez que entre eles havia alemães, austríacos, espanhóis, italianos, franceses e argentinos, sendo apenas um capoeirista brasileiro e um outro português. Em todo o grupo, apenas uma garota francesa era negra.

A trajetória da maioria expressiva destes capoeiristas aponta similaridades com a história de vida narrada por treinel Grego, já que apenas dois membros do Grupo Irmãos Guerreiros de Lisboa não se aproximaram da Capoeira Angola depois de praticar Capoeira Regional e esportes de luta. Ao serem perguntados por que foram atraídos pela Capoeira Regional alguns se referiram à musicalidade, outros ao aspecto da dança, mas todos atribuem à Capoeira Regional uma maior proximidade aos esportes de luta que já conheciam. Ao serem perguntados se conheceram a Capoeira Angola antes da Capoeira Regional, alguns deles responderam que sim, mas que na ocasião não lhes parecera interessante, ao passo que a Capoeira Regional correspondia aos seus anseios: ao mesmo tempo algo diferente (música e dança) e algo familiar relacionado a esportes de luta.

Poderíamos fazer um paralelo entre nossa análise e os estudos realizados por Clara Saraiva (2010) ao analisar a difusão dos terreiros 
de Candomblé em Lisboa. A antropóloga portuguesa percebeu que a trajetória dos filhos de santo iniciava no catolicismo, passava pela Umbanda e findava no Candomblé, gradativamente se distanciando das referências culturais "ocidentais" e se aproximando da cultura afro-brasileira. Para essa análise, Saraiva (2010) usou a ideia de "ponte cognitiva" de Frigerio (2004) e, através desse conceito, entendeu a Umbanda como uma "ponte cognitiva" necessária para que os "ocidentais" pudessem entender e se integrar à cultura afro-brasileira.

Sugerimos que a Capoeira Regional percebida como "esporte de luta exótico" funcionou para os membros do Grupo Irmãos Guerreiros como uma "ponte cognitiva" entre uma linguagem "esportiva" ocidental e outra linguagem "cultural" da Capoeira Angola. Assunção (2014, p. 13), já tinha percebido isso ao seu modo:

Mestre Bimba criou um modelo alternativo de modernização negra para uma tradição de combate de origem africana, um modelo que parece ter sido o único capaz de evitar a ocidentalização ou a folclorização integrais da capoeira. Na verdade, Mestre Pastinha provou, posteriormente, que existia um terceiro modelo para a modernização da capoeira, o qual proporcionava mais uma alternativa ao projeto de Bimba. Em grande medida, entretanto, o modelo de Pastinha só foi viável porque Bimba já havia apontado o caminho.

\section{“Esporte" e “Cultura" na Política Cultural da Capoeira: os Casos Brasileiro e Português}

Após vermos como as ideias sobre "cultura" e "esporte" são mobilizadas pelos capoeiristas para expressar maior ou menor grau de engajamento à "tradição" afro-brasileira, vejamos como esses termos ("esporte" e "cultura") são mobilizados no campo das disputas políticas formais em torno da regulamentação profissional do capoeirista no Brasil e em Portugal. 
Nos dois países, a oposição entre Capoeira "esporte" e Capoeira "cultura" permeia a disputa pela autoridade de definir quem é ou não apto a transmitir o conhecimento da Capoeira: se tomada como "esporte", os mestres deverão se adequar às formas de transmissão e à legislação esportiva vigente se subordinando ao saber erudito da Educação Física ou a centralização das Federações tomadas aqui - para seguir com as falas dos praticantes de Capoeira Angola como organizações pautadas em valores e saberes brancos e ocidentais; por outro lado, caso seja considerada "cultura", os mestres terão maior autonomia para obedecer aos critérios peculiares de suas linhagens, aprendidos oralmente com seus mestres, tomadas aqui, segundo os termos dos angoleiros como linhagens tradicionais da Capoeira (BRITO, 2010).

\section{O CASO BRASILEIRO}

Foi Inezil Pena Marinho, escritor de "Subsídios para o Estudo da Metodologia do Treinamento da Capoeiragem" (1982) o precursor da luta pela regulamentação da Educação Física (EF) como profissão, na década de 1940, o que foi consolidado apenas em 1998 com a aprovação das leis 9615/1998 e 9969/1998. Esse processo deu subsídio ao surgimento do Conselho Federal de Educação Física (CONFEF) e os Conselhos Regionais de Educação Física (CREF's) fundados no ano seguinte.

Segundo essa regulamentação, atividades físicas e esportivas como a Capoeira passavam a ser um nicho profissional exclusivo dos professores com formação universitária em Educação Física. O conhecimento da Capoeira transmitido oralmente e construído por práticas e saberes não institucionalizados poderiam ser legimados, contudo, caso os mestres, que já atuavam no mercado por pelo menos cinco anos antes da entrada da lei em vigor, fizessem uma formação 
complementar com professores de Educação Física na universidade e, obviamente, pagassem por isso.

Nos anos que se passaram, muitos mestres saíram do Brasil em busca de melhores condições de trabalho. Os diferentes títulos de reconhecimento atribuídos pelos governos de outros países (o caso de Mestre João Grande é emblemático ${ }^{3}$ ) chamam a atenção do governo brasileiro que inicia o processo de Registro da Capoeira como o "Patrimônio Cultural Imaterial Nacional", em 2003. O Registro foi realizado com a inclusão do "ofício dos mestres da Capoeira" no Livro dos Saberes e com a inclusão da "Roda de Capoeira" no Livro das Formas de Expressão, em 2008.

O receio da homogeneização cultural produzido pela globalização teria, segundo Fonseca (2008), dado uma nova força ao nacionalismo pela via da cultura segundo uma visão dinâmica, o que gerou Programas de Salvaguarda focados na condição de transmissão dos saberes "tradicionais", relacionados às identidades nacionais. A patrimonialização da Capoeira foi seguida de um plano de salvaguarda voltado a: 1) o reconhecimento do notório saber dos mestres de Capoeira pelo Ministério da Educação; 2) um plano de previdência especial para os velhos mestres de Capoeira e 3) o estabelecimento de um programa de incentivo da Capoeira pelo mundo.

Notemos que a ideia de "tradição" existente no plano de salvaguarda do governo brasileiro nada tem a ver com a sua significação nativa: se para o governo o "saber tradicional" da Capoeira era relacionado a todas as vertentes praticadas no Brasil (Capoeira Angola e Capoeira Regional) lembremos que para os capoeiristas havia uma distinção entre a vertente "tradicional" e a vertente "moderna", respectivamente.

3 Em 1994, a Universidade do estado de Nova Jersey-EUA, Upsala College conferiu ao Mestre João Grande o título de Doutor honoris causa. 
No plano de salvaguarda constava que o saber do mestre não possui equivalente no aprendizado formal do profissional de Educação Física, mas que se estabelece como acervo da "cultura popular brasileira". A proposta pretende contribuir para que mestres de Capoeira sem escolaridade, porém detentores do saber "tradicional" reconhecido, possam ensinar Capoeira em colégios, escolas e mesmo em universidades.

Como propõe Fonseca (2016), o registro da Capoeira como Patrimônio Cultural Imaterial Brasileiro pode ser entendido como uma política de reparação às atrocidades sofridas pela população afrodescendente no Brasil, passando a compor as estratégias de setores desse segmento em suas lutas por direitos.

Munidos com a noção de "cultura" legitimada pelo Registro de Bem Cultural Nacional, capoeiristas mobilizaram senadores e deputados de modo que a questão foi parar no Congresso Nacional: Alice Portugal do PCdoB-BA defendeu a proposta "cultural" de interesse dos capoeiristas e Arnaldo Faria de Sá do PTB-SP defendeu a proposta "esportiva" do CREF/CONFEF.

Em 2009, a lei 9969/98 foi arquivada e os capoeiristas adquiriram autonomia em relação ao CONFEF. Todavia, um segmento dos capoeiristas conseguiram que a PL 31-2009 fosse aceita, de modo que a Capoeira, de modo genérico, também se tornou uma profissão esportiva. Os termos da PL 31-2009 são contidos na Lei 9615/98 (conhecida como "Lei Pelé") que determina que os profissionais do esporte não mais estejam submetidos ao CONFEF, mas obrigatoriamente inseridos em Federações.

Os praticantes de Capoeira Angola se opuseram a essa PL alegando, mais uma vez, que cada grupo deveria decidir, segundo seus próprios critérios, quem deveria ou não transmitir legitimamente os ensinamentos legados pelos seus ancestrais e quais seriam os elementos a serem transmitidos de acordo com cada linhagem. 
Em 2013, a luta política continua. Dessa vez com a participação ativa de um representante dos praticantes da Capoeira Angola, como se lê em um parecer redigido por Adinolfi.

Por fim, finalizo este Parecer pontuando que há que se levar em conta os questionamentos feitos pelo mundialmente reconhecido Mestre de Capoeira Angola, Mestre Cobra Mansa, em texto lido por ele na Audiência Pública sobre o Projeto de Lei no 50/2007, que prevê a transformação da Capoeira em esporte, realizada pela Frente Parlamentar em Defesa da Capoeira, da Câmara de Vereadores de Salvador, no dia 25/10/13, cujo trecho cito abaixo: "Antes de pensarmos em institucionalização da Capoeira, nós temos que perguntar por que querem nos organizar? Porque quereríamos uma instituição para controlar o nosso estilo de vida? Quem vai ganhar com isso? A Capoeira? O capoeirista? Os burocratas? Será que estas instituições são realmente necessárias? Quem as controlará? Porque elas têm que ser tão repressivas, elitistas e ditatoriais? Podemos confiar nestas instituições e nos seus líderes moralmente, financeiramente, fisicamente e espiritualmente? O que é que nós queremos? Nós queremos a institucionalização da Capoeira, ou uma comunidade de Capoeira que trabalhe com "o sistema" para obter honestamente o que precisamos sem nos inclinarmos para o que este sistema tem a nos oferecer? Embora estejamos abertos para crescermos no espírito e conhecimento da Capoeira, queremos evitar a imposição de valores de um grupo de pessoas e burocratas que já tenham criado as suas próprias escalas de valores. Queremos uma comunidade que celebre e encoraje a individualidade e a cooperação entre seus membros; uma comunidade mundial de Capoeira que respeite diferentes valores, crenças, pontos de vista, práticas, etc; em resumo, o que queremos é uma comunidade que respeite as nossas diferentes estórias e histórias, as nossas vidas diferentes e o nosso crescimento em direções variadas para o seu próprio fortalecimento. Pois é isto o que nós todos teremos para oferecer através do entendimento e do amor sobre a prática e o espírito da Capoeira". (INSTITUTO DO PATRIMONIO HISTÓRICO E ARTÍSTICO NACIONAL, 2013). 
Em 2015, a PL 31-2009 foi arquivada e substituída pela PL 17/2014. Essa, por sua vez, diz que a Capoeira no Brasil será entendida nos dois registros, tanto como "esporte" quanto como "cultura", de modo a garantir a autonomia desse profissional em relação a qualquer Federação ou Conselhos profissionais.

\section{O CASO PORTUGUÊS}

Em 2014, aquilo que muitos capoeiristas temiam que acontecesse no Brasil concretiza-se em Portugal. A Federação Portuguesa de Capoeira (FPC), que surgira em 2010, consolida-se como órgão regulador da Capoeira no país de acordo com a legislação esportiva portuguesa. Em seu regimento consta os seguintes objetivos:

1. Homologar graduações dos praticantes de Capoeira pertencente ao edifício técnico da FPC.

2. Reconhecer a legitimidade e atribuir níveis técnicos aos seus praticantes, procedendo ao seu registo e homologação do seu nível, na FPC, mediante Certificação da Associação Nacional de Treinadores de Capoeira PROCAPOEIRA. Compete às Associações enviar anualmente à FPC, o seu programa técnico de Exames de Graduação o qual deve contemplar os tempos mínimos de prática em cada Etapa em conformidade com o Artigo $7^{0}$ do presente regulamento.

Trata-se de uma imensa violência e desrespeito aos valores dos grupos de Capoeira que não concebem a Capoeira com "esporte", sobretudo aos angoleiros, uma vez que nessa modalidade nem ao menos existem "sistemas de graduação" ou competições.

O núcleo lisboeta do Grupo de Capoeira Angola Irmãos Guerreiros se viu em meio ao dilema de se submeter à legislação e negar seus valores "tradicionais" oficialmente ou correr o risco de ter seu espaço interditado. 
No final do ano de 2014, surge mais um elemento nessa conjuntura, a Capoeira foi reconhecida como "Patrimônio Cultural da Humanidade" pela UNESCO. Alguns mestres foram convidados para uma reunião, que teve lugar em Paris, na França, para participarem da votação. Entre eles estavam: Mestre Cobra Mansa, Mestra Janja e seu discípulo Mestre Peter representando a Capoeira Angola e Mestre Duda Pirata, Mestre Paulão Kikongo e Mestre Sabiá representando a Capoeira Regional Estilizada. Na ocasião, a presidenta do Instituto do Patrimônio Histórico e Artístico (IPHAN), Jurema Machado diz:

O reconhecimento internacional amplia as condições de salvaguarda desse bem. Os compromissos assumidos pelo governo para com essa salvaguarda envolvem ações de promoção, de valorização dos saberes dos mestres, seja na inserção no mercado de trabalho, seja na preservação das características identitárias da Capoeira ou na formação de redes de cooperação e de transmissão de conhecimento (BRASIL, 2015, grifo nosso).

O Registro da Capoeira como Patrimônio Cultural da Humanidade foi mobilizado por uma parcela pequena dos capoeiristas portugueses na tentativa de organizar uma resistência à regulação da profissão do capoeirista como esportista pelo governo de Portugal, mas foi em vão, talvez porque tarde demais. A Federação Portuguesa de Capoeira (FDP) e a Secretaria do Desporto já haviam decidido pela entrada da Capoeira no Programa Nacional de Formação de Treinadores (PNFT) à revelia da opinião de considerável parte dos capoeiristas portugueses.

Um dos maiores agentes de resistência à implementação de PNFT para a Capoeira em Portugal foi Ricardo Nascimento (professor de Capoeira e antropólogo), para quem tal Programa configura-se numa forma de arrecadação de verba respondendo aos interesses de uma parcela ínfima do segmento português, tal qual sugeria Mestre Cobra Mansa em seu depoimento supracitado. 
Ricardo buscou intervir junto ao governo português mobilizando agentes internos e externos à prática da Capoeira. Tentou organizar a comunidade capoeirística portuguesa que se opunha ao PNFT, mas percebeu que se, por um lado, a maioria deles havia cedido às determinações da Secretaria e da Federação e adotado seus critérios, por outro, aqueles que se mantiveram contrários à tal decisão não se engajaram politicamente.

Ricardo, sozinho em sua militância, buscou então outra estratégia. Organizou um evento de Capoeira em Lisboa voltado à promoção de debates sobre a regulamentação da profissão do capoeirista em Portugal contando com a presença de pessoas de fora de Portugal: Mathias Assunção (capoeirista e professor de História na Universidade de Essex em Londres, renomado pelos seus estudos pioneiros em Capoeira), Luiz Renato Vieira (Mestre de Capoeira, sociólogo, pesquisador da Capoeira e assessor do IPHAN e do Ministério da Cultura no Brasil) e Mestre Russo ou Jonas Rabelo (reputado Mestre de Capoeira carioca).

[...] Aqui em Portugal ninguém se mexia. Eu chamei todos aqueles que achei que poderiam ajudar na luta porque $o$ negócio foi sério! Para o evento chamei um representante da academia, o Mathias, um representante do estado brasileiro, Renato e um representante da Capoeira de rua do Brasil, Mestre Russo. Tentei com essa galera de peso. A ideia era conseguir revogar essa lei absurda aí que o governo português conseguiu instaurar ${ }^{4}$

Ricardo conseguiu audiências com representantes do Ministério do Desporto português, mas, não alcançando nenhuma alteração, acabou, assim como os outros capoeiristas residentes em Portugal, acatando ao Programa e tentando alterar a lógica governamental "por dentro", criando uma Federação alternativa para disputar o direito de participar na escolha dos critérios a

4 Fala de Ricardo Nascimento em entrevista concedida ao autor deste artigo, na cidade de

Lisboa, em 2015. 
serem avaliados durante o teste para a obtenção da licença. Sua Federação foi aceita e formalizada, porém não lhe foi concedido o direito à participação na regulamentação da profissão do capoeirista. Entretanto, uma das vitórias de Ricardo foi a FPC ter concedido aos diversos professores e mestres de Capoeira filiados a ela o direito de elaborar cursos preparatórios de modo relativamente autônomo. Esta relativa autonomia significou, na prática, uma subversão dos valores "esportivos" defendidos pela FCP em prol dos valores "culturais", além de baixar os custos da filiação ao mínimo possível.

O Curso de Formação de Treinador de Capoeira, elaborado por Ricardo Nascimento, tratou de questões internas ao universo da Capoeira, considerando os distintos entendimentos acerca da musicalidade e a articulação com outras práticas culturais afrobrasileiras e religiosidade afro-brasileira, ao invés de obedecer aos critérios esportivos determinados pela FPC, que requeriam a homogeneização de nomenclaturas de golpes e sistemas de graduação, tempo e critérios para mudança de nível, etapas do treinamento, aquecimento, exercícios e regras para competições.

Os integrantes do Grupo de Capoeira Angola Irmãos Guerreiros de Lisboa, não podendo se ausentar do Programa sob o risco de perderem a licença para manterem o núcleo lisboeta ativo, encontrou na formação proposta por Ricardo uma alternativa para burlar a concepção "esportiva" da Capoeira.

Resta agora saber qual será a continuação dessa dinâmica.

\section{Considerações Finais}

Vimos que tanto intelectuais quanto capoeiristas e políticos mobilizaram as categorias de "esporte" e "cultura" para qualificar distintas práticas da Capoeira durante todo o século XX. No Século XXI, essa dinâmica extrapolou o território nacional instaurando-se também 
na Europa, principalmente em Portugal. Essas mobilizações conceituais refletem dinâmicas sociais e econômicas, assim como disputas políticas inseridas no campo das políticas culturais promovidas tanto pelo Estado brasileiro quanto pelo Estado português.

A concepção "esportiva" da Capoeira associada à Capoeira Regional foi, como escreve Assunção (2014), uma alternativa à ocidentalização e à folclorização da Capoeira durante a primeira metade do século $X X$, abrindo o caminho para a expansão de diferentes concepções da Capoeira tanto geográfica como socialmente. Tal alternativa "esportiva", inclusive, forneceu os meios para a Capoeira Angola, vertente mais próxima da concepção "cultural", ser disseminada.

Referindo-se ao processo de transnacionalização, a concepção "esportiva" da Capoeira se mostrou imprescindível para a aclimatação da Capoeira Angola na Europa, funcionando como uma "ponte cognitiva", nos termos de Frigerio (2004), entre "esportes de luta ocidentais" e a "cultura afro-brasileira tradicional".

Como Fonseca (2016) aponta, o processo de patrimonialização forneceu ferramentas conceituais legítimas aos grupos de capoeiristas para que eles reivindicassem o direito de terem garantida a manutenção de sua especificidade cultural em relação ao saber erudito universitário. Trata-se de uma reivindicação de reparação histórica da exploração e desrespeito para com a cultura afro-brasileira e seus representantes.

Entretanto, se no Brasil, a patrimonialização da Capoeira como Bem Cultural Imaterial possibilitou aos capoeiristas a conquista política da autonomia para gerenciar seus saberes tradicionais, inclusive no mercado de trabalho, em Portugal isso não acontece. Mesmo com o impulso fornecido pelo Registro da Capoeira como Bem Cultural Imaterial da Humanidade, em 2014, aqueles que seguem uma vertente avessa à concepção "esportiva" não conseguem autorregular sua prática da Capoeira, sendo obrigados a financiar uma Federação 
(que nada representa para eles) e se submeter a um conjunto de comportamento e valores avessos aos que acreditam.

Se entendermos a Educação Física ou as Federações segundo os valores nativos dos praticantes da Capoeira Angola veremos que, em Portugal, a Capoeira "cultura" fundamentada na tradição afro-brasileira mantêm-se solapada pelos valores e saberes ocidentais funcionando como uma forma de continuação do processo de colonização ou branqueamento.

$\mathrm{O}$ conhecimento adquirido oralmente por anos a fio de treinamento com um mestre de tal ou qual linhagem que não concebe a Capoeira como um esporte de luta torna-se algo inferior, passível de ser transformado, significando quase que uma revitalização da perspectiva evolucionista que marcou o higienismo no Brasil do início do século $X X$.

Faz-se necessário considerar que a presença do Movimento Negro no Brasil forneceu subsídios ideológicos aos capoeiristas angoleiros que revitalizaram a sua "tradição" fortalecendo, assim, seu caráter político, entendido aqui como o substrato da Capoeira "cultura": fazer capoeira "tradicionalmente" era posicionar-se politicamente. Enquanto que em Portugal, esse elemento político da "tradição" chega enfraquecido, tendo sido enfatizado em seu lugar o aspecto místico e de entretenimento e, nos mesmos termos, sendo a "tradição" o substrato da Capoeira "cultura", seus partidários portugueses permaneceram desmobilizados frente ao embate político formal entre Capoeira "esporte" e Capoeira "cultura", permitindo a formalização da Capoeira somente enquanto modalidade esporte naquele país.

A ironia é que um país identificado pelo termo "imperialista" como os EUA reconhece e valoriza a "cultura afro-brasileira" dos velhos mestres enquanto que o governo português, engajado na formação de uma conexão horizontal entre os Países Falantes de Língua Portuguesa (PFLP) e consciente de ter sido protagonista de 
uma relação de exploração étnica comprometedora reluta em dialogar com intelectuais, capoeiristas e membros do Ministério da Cultura brasileiros que se mobilizaram pela Capoeira "cultura".

Sendo assim, creio que as atuais formas de política cultural da Capoeira contemporânea dependem parcialmente das formas locais de entendimento acerca da "tradição". No que se refere ao caso português, tal "tradição" perdeu parte importante de seu elemento etnopolítico. Além disso, devemos ressaltar o equívoco do governo português em fechar algumas das poucas vias de comunicação com seus companheiros lusófonos ultramarinos. Deveria implementar em sua agenda de política cultural a construção conexões mais horizontais e democráticas para que seja realmente possível a consolidação de um "mundo lusófono" redimido da história colonialista.

\section{REFERÊNCIAS}

AGIER, Michel. Ethnopolitique: racisme, statuts et mouvement noir à Bahia. Cahiers D'études Africaines, Paris, v. 32, n. 125, p. 53-81, 1992.

ASSUNÇÃO, Matthias Röhrig. Capoeira circle or sports academy? The emergence of modern styles of capoeira and their global context. História, Ciências, Saúde, Manguinhos, Rio de Janeiro, v. 21, n. 1, p. 135-150, 2014. Disponível em: <<https:// dx.doi.org/10.1590/S0104-59702014005000002>. Acesso em: 5 mar. 2016.

BRASIL, MinC. Roda de Capoeira recebe título de Patrimônio Cultural Imaterial da Humanidade, 2014. Disponível em <http://www.cultura.gov.br/noticias-destaques/-/ asset_publisher/OiKX3xlR9iTn/content/id/1230742>. Acesso em 15 de março de 2016.

BRITO, Celso de. A transnacionalização da capoeira angola: uma etnografia sobre a geoeconomia política nativa. 2015, 315 f. Tese (Doutorado em Antropologia Social) - Universidade Federal do Rio Grande do Sul, Porto alegre, 2015.

BRITO, Celso de. A regulação da instanciação religiosa na capoeira angola globalizada: a relação entre o grupo irmãos guerreiros e o Ilê Obá Silekê de Berlim, Alemanha. In: REUNIÃO BRASILEIRA DE ANTROPOLOGIA, 30., 2016, João Pessoa. Anais... João Pessoa: UFPB, 2016. 
BRITO, Celso de. A roda do mundo: fundamentos da Capoeira Angola "glocalizada". 2010. 190 f. Dissertação (Mestrado em Antropologia Social) Universidade Federal do Paraná, Curitiba, 2010.

BURLAMAQUI, Aníbal, Mestre Zuma. Ginástica nacional (capoeiragem) metodizada e regrada. Rio de Janeiro: Ed. do Autor, 1928.

CARNEIRO, Edison. Capoeira de Angola. In: Bantos. 2. ed. Rio de Janeiro: Civilização Brasileira, 1981.

FONSECA, Vivian Luiz. A Capoeira Contemporânea: antigas questões, novos desafios. Recorde: Revista de História do Esporte, v. 01, n. 01, 2008. Disponível em: https://revistas.ufrj.br/index.php/Recorde/article/view/795/736. Acesso em 10 de julho de 2016.

FONSECA, Vivian Luiz. O registro da capoeira e a política de preservação do patrimônio imaterial no Brasil: práxis política, luta por direitos e reparação. In: REUNIÃO BRASILEIRA DE ANTROPOLOGIA, 30., 2016, João Pessoa. Anais... João Pessoa: UFPB, 2016.

FRIGERIO, Alejandro. Capoeira: de arte negra a esporte branco. Revista Brasileira de Ciências Sociais, São Paulo, v. 4, n. 10, p. 85-98, 1989.

FRIGERIO, Alejandro. Re-africanization in secondary religious diaspora: constructing a world religion. Civilisations Revue Internationale d'Anthropologie et de Sciences Humaines, Bruxelas, v. 51, p. 39-60, 2004.

INSTITUTO DO PATRIMONIO HISTÓRICO E ARTÍSTICO NACIONAL. Parecer Técnico 0523/2013. Brasília, 2013. Disponível em: <https://www.senado.gov.br/ comissoes/CE/AP/AP20131206_Capoeira_Maria_Paula_IPHAN.pdf >. Acesso em:

MARINHO, Inezil Penna. A ginástica brasileira: resumo do projeto geral. Brasília: Autor, 1982.

ORTIZ, Renato. A morte branca do feiticeiro Negro. Petrópolis: Vozes, 1978.

QUERINO, Manuel. Costumes africanos no Brasil. Rio de Janeiro: Civilização Brasileira, 1938.

SARAIVA, Maria Clara. Afro-Brazilian religions in Portugal: bruxos, priests and pais de santo. Etnográfica, Lisboa, v. 14, n. 2, p. 265-288, 2010.

GRUPO DE CAPOEIRA ANGOLA IRMÃOS GUERREIROS. Disponível em: $<$ http://irmaosguerreiros.wixsite.com/saopaulo>. Acesso em: 5 mar. 2016. 